Bulletin of Advanced English Studies - Vol. 3, No. 1 , 2019, pp. $34-43$

e-ISSN 2617-6459, p-ISSN 2617-6440

Available online at http:// www.refaad.com

https://doi.org/10.31559/baes2019.3.1.4

\title{
Corpus-Based, Genre-Analytic Approach to Discipline-Specific Materials Design and Development
}

\author{
Ali Abdullah Altayeb Alkhalifa \\ English language department, ESP lecturer, Faculty of (MLS) Sudan International University (SIU), \\ Khartoum, Sudan \\ Altaaishy70@gmai1.com
}

\section{Ishraga Bashir Mohammed Elhassan}

\author{
Secretary of the academic affairs. Sudan International University (SIU), Khartoum, Sudan
}

ishragabashirelhassn@gmail.com

\begin{abstract}
The use of corpus linguistics in ELT is a modern method of developing the teaching the researcher has made use of the Corpus-based, genre-analytic approach to design an English text book for the first year of medical laboratory sciences students (MLS). The content teachers of the medical laboratory sciences have provided the designer with a large collection of medical terms and texts and the designers drew language and academic skills around those corpora. The designer has followed the basic criteria of syllabus design and materials development to design this text book. A text book evaluation check list is designed for the English language teachers who had taught the book to evaluate it and find out whether corpus based approach through which the book is designed help to develop it as considerable English text book that can be easily assigned to be taught for the medical lab students in the whole Sudanese universities. The results reveal that the textbook has helped the students to enhance their language competence as well as critical thinking. It also paves the way for the English language teachers to make use of the corpus based approach to develop the materials they teach for their ESP classes.
\end{abstract}

Keywords: corpus linguistics, material design, ESP, textbook, university

\section{Introduction}

Education of a foreign language opens new prospects of mobility and collaboration for professionals to exchange and develop ideas. Education experts acknowledge the role that foreign languages, especially English, play in the professional development of future specialists. Corpus linguistics is one of the technology-based tools that could be very useful in teaching but still has not been widely used or tested. Nevertheless, in the last 30 years, the use of corpora in classrooms has started to develop (Willis 1998).The analyses of specialized corpora (i.e., large collections of medical laboratory sciences texts) help describe language in detail, providing data that can be easily transferred to pedagogical contexts

Thus, corpus-based language analyses have become an invaluable tool for the design of materials for language for specific purposes as language learners need to master the specific discourses used in their new language communities to become successful members of those communities. The study focuses on characteristics of English for Specific Purposes (ESP). The research outlines the approaches to ESP curriculum development and planning. It identifies the prerequisites and methods of analyzing learners' expectations and goals. The study determines what components of course content help to align aims, form, and conditions of educational activities with 
the students' future professional roles. This study presents the findings from an ESP curriculum development project designed and developed for Medical laboratory Sciences students at Sudan International University. Students learning needs will be analyzed to identify student's interest in ESP program, their language needs and experience regarding their intellectual production and their perceived importance of different language sub-skills in both the local and international contexts are considered. The study describes the main results derived from an ESP text book with a focus on medical laboratory sciences corpora. The main argument is that corpora can be integrated in language classrooms. The research also points out other elements that affect the use of corpus such as the role of the teacher and the challenges that face both students and teachers when using corpora. The researcher will also present a number of ideas for planning corpus-based activities. Those activities are tailored so that they meet the different language abilities of students in L2 classrooms. The research will demonstrate how vocabulary, grammar, idiomatic expressions and pragmatic constraints could be covered in EFL classrooms using corpus-based resources.

\section{Background and Statement of the Problem}

Corpora can be extremely useful in language teaching in general and ESP in particular. With reference to ESP, the use of corpora, with the appropriate training, can be valuable for teachers and learners, who can gain insights into the workings of the language and into the specific linguistic features of the genres and disciplines they are involved in. It may also contribute greatly to autonomous learning which is of utmost importance for students at that level.

The drawback emerging from the commercial textbooks scheduled for first year inspired the researcher to develop a textbook that is relevant to the students' discipline and can overcome the motivational shortcoming and exploit different teaching methods, and stimulate a linguistically non-homogeneous group struggling to find their way between university requirements and study habits peculiar to secondary school instruction. Thus, corpus-based language analyses have become an invaluable tool in the materials design for, language for specific purposes (ESP) as language learners need to master the specific discourses used in their new language communities to become successful members of those communities. It has been observed that combining corpus analysis with genre analysis provide data that can be easily transferred to pedagogical contexts. Corpus linguistics is not concerned with what is possible in a language but in what is probable (Hanks,2013) .So it is one of the technology-based tools that could be very useful in teaching but still has not been widely used or tested especially in Sudanese tertiary education context.

\section{The Aims of the Study}

The Study aims at:

1. Examining the use of corpora in designing ESP courses

2. Presenting the combing of corpus analysis and genre analysis approach

4. Evaluating the medical laboratory sciences program

\section{The Hypotheses of the Study}

The research hypotheses the following:

1. Combining corpus analysis with genre analysis provides data that can be easily transferred to pedagogical contexts

2. Corpora components of ESP program helps to align aims, form, and conditions with the Students discipline

3. corpus-based language analysis helps to align aims, form, and conditions with the students' profession 


\section{Methodology}

A textbook evaluation checklist will be designed for the English language teachers to evaluate the text book they teach to the first-year students in the Faculty of Medical Laboratory Sciences, Sudan International University for the academic year 2014-2015.

\section{Literature Review}

\section{- Evaluation Checklist Approach}

Researchers use checklists to evaluate the text books so as to see whether they match the students' needs. McGrath (2002) sees that using the checklist approach ensures that the relevant items are considered for evaluation. So the evaluation checklist should be well designed and contain clear and concise evaluation criteria.

There are two types of evaluation checklists: pre use evaluation checklist and post use evaluation checklist to measure the outcomes of the text books.

There is no universal check list text book evaluation so teachers should identify their own teaching needs and develop different criteria for different contexts.

Littlejohn(1998) states that text book evaluation frames is to help its users to arrive at their own conclusion but not to decide for them on what are the desirable qualities of a text book.

So it is recommended that teachers can tailor their own criteria to meet the students' needs since the off- shelves evaluation checklists are abstract and difficult to respond.

\section{- Principles of ELT Materials Development}

Tomlinson (2012) expresses his preference for materials development as an on-going process of evaluation driven by a set of agreed principles. Both universal ones applicable to any type of learning context and then local criteria specific to the target language context.

Teachers and syllabus designers should be aware of what is significantly meant by materials development. According to Pardo and Téllez (2009) "It includes adaption, creation of learning and teaching exercises, a task, an activity, a lesson, a unit, or a module composed of several units."

Jolly \& Bolitho's (2011) goes further and suggests that dynamic approach to materials production and adaptation imply that teachers should trial their materials with their classes and then modify them according students' feedback and suggestions.

So it is the teachers' role to decide upon which suits his students and then supplement the materials or work them out so that they match the learners' needs and interests.

Furthermore, when teachers or the syllabus designers plan and draft their materials, they never exclude their inspiration because they have clear and well-supported concepts, while designing in opportunistic ways that always consider the students' needs first. Tomlinson (2012).

Tomlinson (2012) continued adding that In order to develop the ELT materials, teachers should consider the following applications

1- Theories of language acquisition and development

2- Principles of teaching.

3- Current knowledge of how target language is actually used

4- Results of systemic observation and evaluation of materials in use.

Teachers should be quite considerable of these applications so that they can easily develop the materials they teach and it is even far better for the materials to engage the students by encouraging them to apply their developing skills to the world beyond the classroom.

The development of the materials in such a way that addresses the learners' needs will help them to provide opportunities to use the target language to achieve communicative purpose. 
It also is recommended to develop or supplement the ELT materials, teachers should take a balance of approaches in the way things are covered, inductive, deductive, and affective approaches to grammar, fluency and accuracy work. Hall (2000)

\section{- Corpus-based Approach}

In the world of modern technology with the increasing amount of electronically stored data available, it is high time to shift from readymade contents books to tailoring your own ones based on corpus based material since such corpora can also underpin syllabuses and course books materials. (MacCarthy, 2004)

"Teachers can adopt a more rigorous approach to materials selection. Rather than simply following the contents of textbooks or intuitions of field specialists, teachers can locate real-world samples of target language, and then analyze these to find new and interesting patterns of language usage" (Thomas \& Short, 1996).

In this paper the researcher has consulted the medical laboratory sciences Corpus with the help of the content teachers who provide him with texts and medical terms that help him to represent and use the language in a variety of contexts matching the students' chosen discipline.

Within this corpus, many samples of medical laboratory sciences consultations can be found, providing a considerable amount of words. Admittedly, many of these samples are related to the language the students need to use during their university study in the faculty of medical laboratory, and so a more careful search for examples of such interactions of the students and their content teachers would normally be required. However, despite the limitations of the data used here, the principles are the same.

It is the roe of the ESP teacher to analyze this and other samples to arrive at a general picture of the language of medical laboratory interaction which needs to familiarize the students with very few technical words.

This leads to more reliable, higher quality materials that students can identify with and see the relevance of.

\section{- Corpora for ESP}

Corpora are definitely the collections of homogeneously-encoded computer-readable text compiled for linguistic purposes. It has been widely used in ESP to derive frequency of lists of words and phrases to improve description of particular genre or discipline specific terminology and discourse. (Boulton, 2012)

The first of these pedagogic uses of corpora has a long-established tradition in ESP. Well before the advent of the computer, researchers had created and analyzed corpora manually as an aid to syllabus and materials design.

The growth of ESP in universities in the 1970s and 1980s coincided with the spread of personal computers and of optical character recognition and concordance software, allowing researchers to create and analyse their own corpora of specific domains with far greater ease. For instance, Skehan (1981) wrote a simple programme to analyze a corpus of economics texts with the aim of identifying the proportions of general, sub-technical, and specialised lexis. He concluded that "if our aim is to put [ESP] students into a position from which they can understand $80 \%$ to $90 \%$ of the total running words in texts, the emphasis in vocabulary teaching must be on sub- technical words.

The designer of the text book of medical laboratory sciences under this study is based, make use of medical lab. Corpora and analyzed them to count for the particular features as well as concordance of the listing of the contextualized examples of medical lab features. 


\section{- The Review of the Medical Laboratory English Text book}

(Young 2011) claims that modern textbooks are called upon to satisfy not only the linguistic needs of the learners but also to help teach competencies, skills, and powerful knowledge. Based on this assumption the researcher designs the book of the medical laboratory sciences to address the students' needs and the area of their interest and specialty. Making use of the students' medical corpus.

The text book is designed to guide lines the students of medical laboratory sciences and put them on their medical right track because the text book tend to make use of the medical laboratory corpora and transfer it into a pedagogical context.

The manuscript of the text book was reviewed by experts and teachers at this level. The manuscript of the text book is published after modifying the manuscript in the light of the suggestions made by the reviewers.

The objectives of the text book are to familiarize the students with their vocabulary and to provide them with the basic language and academic skills they need to cope with their study as well as to attain communicative competence in using English at various levels. Another objective is to introduce different language function within the medical laboratory sciences situation and the main focus is on the language skills.

The methodological frame of the textbook is a kind of integration of theme based, structure based and ESP of medical laboratory corpora. So it is a functional approach and the principals of communicative competence.

The lessons of the text book are introduces in the thematic units and with pre tasks, exercises and task activities.

The organization of the text book is as follow:

The book is divided into units. It consists of twenty units. Every unit begins with the vocabulary section where the all vocabulary is related to the medical laboratory context and within the theme of the unit e.g. unit one is about our body. So the whole vocabulary is about the parts of the body and the collocations of these terms.

The vocabulary activities are designed to help the students recycle and consolidate the key terms of their basic chosen discipline.eg matching exercises, completion, cross the odd word out, word formation and so forth.

The second section of each unit is grammar focus. Most of the grammar is based on the vocabulary (section one) for example how to help the students to construct sentences using the vocabulary they have come across in the first section.

So the grammar is presented in this section communicatively and within the frame of the theme of every unit. In unit one the grammar focus is on the verbs to be. So the students know how and where to use them to write a good descriptive and definition sentence.

The third section is listening. The students experienced daily life communication demonstrated by native speakers. The activities are designed to help the students use the listening activities communicatively e.g. open ended questions, guessing game, completion, and inferences.

The fourth section is speaking. The speaking topics and activities focus on different situations such as introducing yourself to your colleague in unit one, apology, invitation, showing direction and invitations.

So the speaking activities prepare the students towards practicing some of the academic skills the text book consider in its context such as presentations, summary and paraphrasing as well as group discussion.

The speaking activities are in the form of role playing and open discussions. Some of the speaking activities are drawn from the reading texts to train the students for the analytical reading e.g. the students are asked to study and explain what they read in the reading texts in order to help them interact and infer every time they consult or read something. 
The fifth section is reading. Most of the reading texts are provided by the content teachersand comprehending questions are given at the end of the text. There are miscellaneous reading activities; before reading activities after reading and while reading. Some reading activities recycled some language focus e.g. the word formation where the students are asked to change the classification of a chosen word from the reading passage and then reconstruct the whole sentence.

The sixth section is writing. The text book provides some writing basics leading the students from the phrases, clauses into different types of sentences as well as paragraph writing, punctuation and linking words and ideas.

The last section is called skills corner. This section presents the basic academic skills the students need in their study ;such as the art of the presentation, note taking, paraphrasing and summary, using the library, time management, lab safety and so forth.

\section{- The Procedure of Designing the Textbook.}

The text book evaluation check list is designed using standard scale, which is running from excellent, very good, good, poor and not for the English language teachers in order to evaluate the text book designed for the medical laboratory students.

The population is sixty English language teachers. The teachers are provided with the copy of the text book for about a month before the beginning of the students' sessions. Then a three days work shop was held for the teachers to orient them with the content and the objectives of the text book.

During the work shop two demonstrations classes are taught by the researcher. So the English language teachers were highly oriented with the purpose of the checklist.

The textbook has been taught for five weeks four hours a day that is 120 credit hours. The sixty teachers have taught the text book during the preparatory university course. Then after that the researcher distributed the evaluation check list for the teachers. The checklist scale items are analyzed by SPSS software.

The evaluation checklist was revised by five $\mathrm{PhD}$. holders who are expert in the field of syllabus design. They reviewed it and commented upon it and ask the researcher to do some amendments.

Concerning the reliability as it is clearly stated by Nunn (1998) "Measurements are reliable to the extent that they are repeatable and that any random influence which tends to make measurements different from occasion to occasion or circumstance to circumstance is a source of measurement error ".

The researcher followed the technique of the Test-retest reliability which is the degree to which scores are consistent over time. So, ten of the evaluators are asked to view, code or rate the same single statement twice in different times to ensure that the same result is reached. By doing so ,the researcher can easily spot the score variation that occurs from testing session to testing session as a result of errors of measurement. The reliability of the observation checklist was scored high.

\section{The Results}

Table (1): The responses (in percentages) to the textbook evaluation checklist

\begin{tabular}{|l|l|l|l|l|l|}
\hline \multicolumn{1}{|c|}{ Statement } & \multicolumn{1}{|c|}{ Excellent } & v. good & good & \multicolumn{1}{|c|}{ poor } & \multicolumn{1}{c|}{ Not sure } \\
\hline 1- the suitability of content of the book & 33.3 & 50.0 & 8.3 & 8.3 & 8.1 \\
\hline 2-the integration of the scientific terms & 33.3 & 33.3 & .1 & 25.0 & 8.3 \\
\hline 3-the objectives of the book are achievable & 50.0 & 33.3 & & 8.3 & 8.3 \\
\hline 4-The content matches the students' chosen discipline. & 66.7 & 26.7 & & 3.3 & 3.3 \\
\hline 5- the grammar is communicative presented & 50.0 & 33.3 & 33.3 & - & - \\
\hline 6- the grammar activities are well graded & 41.7 & 43.3 & - & 8.3 & 6.7 \\
\hline 7- The vocabulary of the textbook is a medical corpora. & 65.0 & 31.7 & 3.3 & - & - \\
\hline
\end{tabular}




\begin{tabular}{|l|l|l|l|l|l|}
\hline 8- the integration ESP within the language components & 58.3 & 8.3 & 1.7 & 8.3 & 16.7 \\
\hline 9- the reading comprehension texts & 50.0 & 25.0 & 8.3 & 5.0 & 11.6 \\
\hline 10- the writing activities & 66.7 & 33.3 & - & - & - \\
\hline 11- the academic skills and the reading passages & 56.7 & 36.7 & - & 6.7 & - \\
\hline 12- the presentation of the academic skills & 68.3 & 20.0 & & 11.7 & \\
\hline 13- the listening activities & 46.7 & 33.3 & 6.7 & 6.7 & 6.7 \\
\hline 14- the integration of listening and speaking activities & 36.7 & 46.7 & 13.3 & 3.3 & - \\
\hline 15- the speaking section & 38.3 & 28.3 & 16.7 & 11.7 & 5.0 \\
\hline 16- the presentation of the speaking activities & 55.0 & 45.0 & - & - & - \\
\hline 17- the book enhances the students' language proficiency & 43.3 & 23.3 & 16.7 & 10.0 & 6.7 \\
\hline
\end{tabular}

\section{- The interpretation of the results}

The table above shows clearly that the text book is considerably addresses the medical students needs since the content is relevant to their basic chosen discipline.

2 -About $70 \%$ of the respondents agree that the content of the book is related to the students' specialty because it is based on the medical corpora analytical genre approach and then it arouses their interests.

It is clear from the table above that the text book has clear achievable objectives because it familiarizes the students with the medical lab terms in a very systematic linguistics format.

It also helps the students develop their linguistic competence as well as their critical thinking.

The respondents believe that the students enjoy the text book very much and they even interact with it because it is cohesively linked to their medical lab basic subjects.

Moreover, It is obvious that the teachers have found the text book grammar section is communicatively engaged and designed around the ESP vocabulary in order to it enable the students to build very good English sentences with the help of the vocabulary they recycled during both the English classes and their basic subjects.

At the same time the respondents simply agree that the language activities are graded and constructed to reinforce the students' grammar knowledge and therefore, help them to use it communicatively

As well as the teachers undoubtedly agree that the vocabulary is ESP for medical laboratory sciences as it is taken from the students' medical corpora as they asked the content teachers to provide them with a large collection of the medical laboratory sciences texts.

It is also noticed that $75 \%$ of the teachers have found out that it is easily to identify the role of grammar structures drawn with the medical constrains of the text book. So the students fluently interact during their basic classes.

Additionally, the results depict that 45 respondents with $75 \%$ have found out that the reading texts are addressing the medical and they are around the ESP frame. So they enhance the students' reading skills.

Considerably, the whole teachers agree that the writing activities are basics and address the student's basic writing problems.

It is clear from table (10) that the academic skills like presentation, taking notes and paraphrasing are integrated within the reading passages of the text book so the students can make use of the reading passages for example and practice them as presentation topics.

Consequently, the majority of the evaluators in this table are quite satisfied with the academic skills presented in the text book and they see that as they help the students engaged actively in their classes as well as in many group discussions and seminars.

It worth mentioning that results reveal that the listening activities and texts are authentic and thematically address the students' communication needs because they are demonstrated by native speakers and they are the most common situations the respondents as well as the students encounter and benefit from. This is why 48 out of 60 of the respondents have found that the listening section is matching the students' needs 
The students' speaking skill is improving and the teachers have attributed it to the integration of the listening section and speaking section so that the students can demonstrate the phrases and the expressions they encounter in the listening section and use them when they speak.

The table shows the respondents opinions that the speaking section tend to emerge the whole linguistic items the students came across because the speaking situations are related to the students daily life. And even more the speaking activities recycle the language components of the grammar section as the situations are significantly drawn and chosen to help reinforce the language elements presented in the text book.

Most of the respondents see that the speaking activities are graded and progressively distributed in terms of the weight and presentation so forth they help the students practice effectively.

Finally, the text book as it is clear from the responses above help the students develop their language competences and the progression on their chosen discipline as they show great advancement in their basic classes' results and they do not suffer to understand and interact with the main subject when they attend the classes or consult references.

\section{8. $\quad$ Findings}

The study has come out with the many significant outcomes and findings. Firstly, Combining corpus analysis with genre analysis provide data that can be easily transferred to pedagogical contexts as well as the corpus-based language analysis helps to align aims, form, and conditions with the students' profession

Second, the text book is related to the students' medical laboratory field and it helps them to deal with it seriously although it is a required course.

Since the organization of the content of the book helps the students to appreciate the book as it provides them with the key terms of their medical classes.

Third, the text book has clear achievable objectives because it familiarizes the students with the medical lab terms in a very systematic linguistics format. Besides, the grammar section is communicatively engaged and designed around the ESP vocabulary in order to enable the students to build very good English sentences with the help of the vocabulary they recycled during both the English classes and their basic subjects.

Fourth, the language activities have reinforced the students' grammar knowledge and therefore, they use it communicatively.

The study is also depicted that the text book helps the students to get familiarized and enrich their medical laboratory key vocabulary And at the same time the grammar structures drawn with the medical constrains of the text book help the students to interact fluently during their basic classes.

Additionally, the reading texts are addressing the medical context and they have enhanced the students reading skills.

Similarly, the writing activities are basics and have addressed the student's basic writing problems. So the students have showed a significant progress in their writing skill.

The reading passages of the text book have enhanced the students' academic skills because they are presented in the text book to help the students engaged actively in their classes as well as in many group discussions and seminars.

Furthermore, the listening activities have matched the students' needs and improve their listening and speaking skills respectively.

The study also comes out with the result that the students break their speaking psychological fears and they have involved in the group discussion as it is one of the learning techniques in the college and they far better get in positive contact with the international students.

Consequently, the students' speaking skill is improving and the teachers have attributed it to the integration of the listening section and speaking section so that the students can demonstrate the phrases and the expressions they encounter in the listening section and use them when they speak. 
In conclusion, the text book has helped the students develop their language competences and they achieve a considerable progress in their chosen discipline as they show great advancement in their basic classes' results and they do not suffer to understand and interact with the main subjects when they attend the classes or consult references.

\section{Conclusion}

The aim of this study was to examine the use of corpora in designing ESP courses and to present the combing of corpus analysis and genre analysis approach as well as to analyze the different approaches of material development. The designer of this text book has followed the corpus based analytical genre approach to develop and design the ESP course book taught for the students of the medical laboratory sciences at Sudan international university. It is a quantitative research because the researcher has adopted a tailored text book evaluation check list for the English language teaches to evaluate the English text book taught for the medial laboratory students designed by the researcher.

The majority of the evaluators have found that the use of corpus based approach to design or to supplement the text book they teach helps the student to enhance and develop their language competence as well as their critical thinking towards their chosen discipline.

\section{Recommendations:}

The study recommends the following:

1- English language teachers should practically and significantly consider the corpus based approach when designing a text book or supplement the ESP materials they plan to teach. So It is advisable that English teachers should make use of the corpus based genre approach to supplement the ESP text book they teach.

2- University departments should create like a web site or any electronic accesses to the content materials they teach. These materials have to be accessible to the English language department so that teachers can integrate them in their English classes and therefore, the students will use the basic vocabulary communicatively.

3- The study encourages the Teachers to design the materials of the English courses so that they meet their students' actual needs.

4- The study encourages the teachers to develop a unit of language materials using a natural integration based on criteria derived from different approaches of syllabus design

5- The study also draws the teachers' attention to discuss and describe how the curriculum should be developed, and how to integrate the four skills as naturally as possible.

\section{References:}

[1] Boulton, Alex, Data-driven learning: Taking the computer out of the equation, Language Learning, 60(3)(2010), 534-572, https://doi.org/10.1111/j.1467-9922.2010.00566.x

[2] Hall. J. K. \& Eggington. W.G, (Ed), The sociopolitics of English language teaching. Clevedon, OH: Multilingual Matters, (2000)

[3] Hanks. Patrick, Lexical Analysis: Norms and Exploitations. Cambridge, MA: MIT Press, (2013)

[4] Jolly.D. \& Bolitho. R., A framework for materials writing. In B. Tomlinson (ed.), Materials Development and Language Teaching, Cambridge: Cambridge University Press, (2011) 
[5] Littlejohn. A., The analysis of language teaching materials: Inside the Trojan horse. In B. Tomlinson (Ed.), Materials development in language teaching (pp. 190-216), Cambridge: Cambridge University Press, (1998)

[6] Mccarthy. Michael, Touchstone: From Corpus to Coursebook. Cambridge: Cambridge University Press, (2004)

[7] McGrath. I., Materials evaluation and design for language teaching, Edinburgh: Edinburgh University Press, (2002)

[8] Nunan. D., Syllabus design, Oxford University Press, (1988)

[9] Pardo. A. N. \& María Fernanda Téllez. T., ELT Materials: The Key to Fostering Effective Teaching and Learning Settings Materials, (2009)

[10] Skehan. P., ESP teachers, computers and research, ELT documents, 112(1981), 106-125.

[11] Thomas. J. \& Short. M. (Eds.), Using Corpora for Language Research, London: Longman.

[12] Tomlinson. B., Principles of effective materials development. In Harwood, N. (Ed.), English language teaching materials: Theory and practice (pp. 81-108). New York: Cambridge University Press, (2010)

[13] Tomlinson. B., Materials Development for Language Learning and Teaching, Language Teaching, 45(2) (2012), 143-179, https://doi.org/10.1017/s0261444811000528

[14] Willis. J, Concordances in the classroom without a computer, In B Tomlinson (Ed.) Materials development in language teaching, Cambridge, (1998)

[15] Young. M., What Are Schools for? Educaçåo Sociedade \& Culturas, 32(2011), 145-156. 